\title{
DETEKSI KERUSAKAN DAN KELAYAKAN BAN MOBIL BERDASARKAN EKSTRAKSI TEKSTUR MENGGUNAKAN GRAY LEVEL COOCCURRENCE MATRIX DENGAN METODE JARINGAN SYARAF TIRUAN
}

\author{
Nugroho Febriyanto ${ }^{1}$, Dr. Eng. Cahya Rahmad, S.T., M.Kom. ${ }^{2}$, Candra Bella Vista, S.Kom., MT. ${ }^{3}$ \\ 1,2,3 Program Studi Teknik Informatika, Jurusan Teknologi Informasi, Politeknik Negeri Malang \\ ${ }^{1}$ nugrohofebriyanto15@gmail.com, ${ }^{2}$ cahya.rahmad@polinema.ac.id, ${ }^{3}$ bellavista@polinema.ac.id
}

\begin{abstract}
Abstrak
Penyebab kecelakaan di Indonesia salah satunya adalah faktor dari kondisi kendaraan yang tidak baik salah satunya kondisi ban yang mengalami kerusakan. Jenis kerusakan ban mobil terdiri dari empat jenis yaitu ban mobil aus, ban mobil aus pada bagian tertentu, ban mobil retak atau terkena paku, ban mobil pecah atau robek. Faktor lainnya yaitu kurang kesadaran atau kelalaian dari pengguna mobil untuk selalu memeriksa kondisi kendaraan terutama kondisi ban sebelum digunakan. Untuk mengatasi hal tersebut maka diusulkan untuk membuat sistem pendeteksi kerusakan dan kelayakan pada ban mobil berbasis Digital Image Processing (Pengolahan Citra Digital). Pada skripsi ini menggunakan citra ban mobil untuk didekteksi jenis kerusakan pada ban tersebut berdasarkan tekstur menggunakan Gray Level Cooccurrence Matrix. Backpropagation digunakan untuk mengklasifikasikan jenis kerusakan ban mobil dari nilai ekstraksi tekstur. Pada 100 kali pengujian menunjukkan tingkat akurasi metode Backpropagation adalah $80 \%$. Faktor yang mempengaruhi tingkat akurasi yaitu proses pengambilan citra, kondisi ban mobil yang akan diambil citranya, nilai parameter yang digunakan untuk klasifikasi, dan perubahan nilai parameter yang tidak signifikan. Selain itu pengguna kendaraan dapat mengirimkan kondisi ban mereka melalui aplikasi android yang dibuat pada skripsi ini untuk diketahui jenis kerusakan dan tingkat kelayakan. Sehingga pengguna mobil dapat mengambil keputusan untuk mengganti ban mobil tersebut atau tidak.
\end{abstract}

Kata kunci : Kerusakan Ban Mobil, Tingkat Kelayakan Ban Mobil, Pengolahan Citra Digital, Ektraksi Tekstur, Gray Level Cooccurrence Matrix, Backpropagation.

\section{Pendahuluan}

Ban adalah salah satu komponen yang dimiliki pada setiap kendaraan bermotor. Ban bisa dipakai pada beberapa kendaraan seperti mobil, motor, sepeda dengan tipe dan ukuran ban yang berbeda-beda tergantung kepada kendaraan itu sendiri. Ban yang ada pada setiap kendaraan tidak selamanya bisa dipakai karena struktur dari ban itu sendiri terbuat dari karet yang diolah sedemikian rupa. Ban juga memiliki kerusakan yang dapat menimbulkan dampak bagi pengguna kendaraan yaitu kecelakaan. Ada beberapa jenis kerusakan yang terjadi pada ban antara lain aus (Irregular Wear), aus pada bagian tertentu (Spot Wear), retak / terkena paku (Tread Cut Penetration), robek (Cut Brust) (Prasetyadi, 2016). Sehingga jika dibiarkan dalam jangka waktu tertentu dapat menyebabkan terjadinya kecelakaan.

Perkembangan teknologi saat ini memang sangat pesat dan memiliki peran penting untuk membantu setiap permasalahan dalam berbagai bidang, salah satu inovasi perkembangan teknologi saat ini adalah pengolahan citra. Pengolahan citra adalah pemrosesan citra menjadi citra lain untuk tujuan tertentu, misalnya untuk mendapatkan kualitas citra yang baik. Karena perkembangan teknologi saat maka proses pengolahan citra dapat dilakukan secara digital dengan memproses citra dengan melakukan operasi-operasi pemrosesan sinyal dengan menggunakan computer (Putra, 2010).

Berdasarkan pemaparan dari permasalahan diatas muncul gagasan untuk membangun sebuah Rancang Sistem Deteksi Kerusakan dan Kelayakan Ban Mobil Berdasarkan Ekstraksi Tekstur Gray Level Cooccurrence Matrix Menggunakan Jaringan Syaraf Tiruan yang memanfatkan konsep dasar dari Pengolahan Citra Digital. Sistem ini memiliki acuan citra ban berdasarkan tekstur untuk mendeteksi kerusakan, hasil dari ekstraksi fitur tersebut adalah jenis kerusakan pada ban mobil seperti, ban yang aus, aus pada bagian tertentu, ban retak, ban robek. Keempat jenis kerusakan ban mobil diatas dapat dilihat dari citra permukaan ban yang telah didapat. Data dari citra permukaan ban tersebut akan diolah untuk mendapatkan teksturnya menggunakaan Gray Level Cooccurrence Matrix untuk mendapat jenis kerusakan apa yang ada pada ban mobil tersebut. Jenis Kerusakan ini, selanjutnya akan diklasifikasikan 
menggunakan metode Jaringan Syaraf Tiruan yaitu Backpropagation. Untuk tingkat kelayakan yang digunakan merujuk pada hasil klasifikasi jenis kerusakan ban mobil antara lain: layak untuk kategori Fine Wear, setengah layak untuk Irregular dan Spot Wear, tidak layak untuk Tread Cut Penetration dan Cut Burst.

\section{Landasan Teori}

\subsection{Citra}

Citra adalah gambar pada bidang dwimarta (dua dimensi). Ditinjau dari sudut pandang matematis, citra merupakan fungsi menerus dari intensitas cahaya pada bidang dwimarta. Sumber cahaya menerangi objek, objek memantulkan cahaya kembali sebagian dari berkas cahaya tersebut. Pemantulan cahaya ini ditangkap oleh alat-alat optic, misalnya mata pada manusia, kamera, pemindai (scanner), dan sebagainya, sehingga bayangan objek yang disebut citra tersebut terekam (Munir, 2004). Citra adalah suatu gambaran atau kemiripan dari suatu objek. Citra analog tidak dapat direpresentasikan melalui komputer, sehingga tidak bisa diproses oleh komputer secara langsung. Citra analog harus dikonversi terlebih dahulu ke citra digital (Andono, Sutojo, \& Muljono, 2017).

\subsection{Pengolahan Citra Digital}

Pengolahan Citra digital merujuk pada pemrosesan citra 2 dimensi menggunakan Komputer. Dalam konteks yang lebih luas, pengolahan citra mengacu pada pemrosesan data 2 dimensi. Citra digital merupakan citra yang memiliki sebuah larik (Array) yang berisi nilai-nilai real maupun komplek yang direpresentasikan dengan deretan bit tertentu. Suatu Citra dapat didefinisikan sebagai fungsi $f(x, y)$ berukuran $\mathrm{M}$ baris dan $\mathrm{N}$ kolom, dengan $\mathrm{x}$ dan $\mathrm{y}$ adalah koordinat spasial, dan amplitude $f$ di titik koordinat $(x, y)$ dinamakan intensitas atau tingkat keabuan dari citra pada titik tersebut. Apabila nilai M, $\mathrm{N}$ dan nilai amplitudo $f$ secara keseluruhan bernilai (Infinite) dan bernilai diskrit maka dikatakan bahwa citra tersebut adalah citra digital (Putra, 2010).

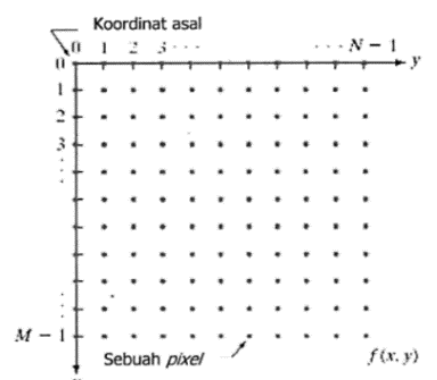

Gambar 1. Koordinat Citra Digital

Fungsi $f(x, y)$ pada suatu citra dalam bentuk matrik sebagai berikut :

$$
f(x, y)=\left[\begin{array}{cccc}
f(0,0) & f(0,1) & \ldots & f(0, N-1) \\
f(1,0) & f(1,1) & \ldots & f(1, N-1) \\
\vdots & \vdots & & \vdots
\end{array}\right]
$$

Gambar 2. Fungsi f(x,y) Pada Citra Digital
Nilai pada suatu irisan antara baris dan kolom (pada posisi $\mathrm{x}, \mathrm{y}$ ) disebut dengan picture element, image element, pels, atau pixels. Istilah terakhir (pixel) paling sering digunakan pada citra digital (Putra, 2010).

\subsection{Ban}

Ban adalah bagian yang berhubungan langsung dengan permukaan jalan. Fungsi ban adalah untuk memperoleh gaya gesek yang lebih besar dengan permukaan jalan yang menghasilkan pergerakan mobil lebih nyaman dengan menyerap kejutan-kejutan yang ada di jalan (Agustian, 2014).

\subsection{Gray Level Cooccurrence Matrix}

Gray Level Cooccurrence Matrix yang dikemukakan oleh Haralick merupakan salah satu metode statistikal untuk ekstraksi tekstur dan termasuk yang paling banyak digunakan dalam teknik analisis tekstur (Rahmad, Astiningrum, \& Lesmana, 2018). Gray Level Cooccurrence Matrix dibentuk dari suatu citra dengan melihat pada piksel-piksel yang berpasangan yang memiliki intensitas tertentu. Penggunaan metode ini didasarkan pada hipotesis bahwa dalam suatu tekstur akan terjadi perulangan konfigurasi atau pasangan keabuan. Misal, d didefinisikan sebagai jarak antara dua posisi piksel, yaitu (x1, y1), (x2, y2); dan $\theta$ didefinisikan sebagai sudut diantara keduanya. Orientasi sudut $\theta$ terdiri dari empat interval sudut yaitu $0^{\circ}, 45^{\circ}, 90^{\circ}$, dan $135^{\circ}$.

Matrik ko-okurensi dinyatatakan sebagai $\operatorname{Pd}, \theta(i, j)$. suatu piksel bertetangga yang memiliki jarak d diantara keduanya dan teletak pada empat interval sudut yang berlainan (Asmara, Puspitasari, Romlah, H, \& Romario, 2017). Pada penelitian ini menggunakan 5 ciri tekstur dari 11 ciri tekstur yang terdapat pada Gray Level Cooccurrence Matrix yaitu:

$$
\begin{aligned}
& A S M(\text { Energy })=\Sigma_{i} \Sigma_{j} P^{2}[i, j] \\
& \text { Entropy }=\Sigma_{i} \Sigma_{j} P[i, j] \log P[i, j] \\
& \text { Homogenity }=\Sigma_{i} \Sigma_{j} \frac{P[i, j]}{1+|i-j|} \\
& \mu_{i}=\Sigma_{i} \Sigma_{j} i P[i, j] \\
& \mu_{i}=\Sigma_{i} \Sigma_{j} i P[i, j] \\
& \sigma_{i}=\sqrt{\Sigma_{i} \Sigma_{j}(i-\mu i)^{2} P[i, j]} \\
& \sigma_{j}=\sqrt{\Sigma_{i} \Sigma_{j}(i-\mu j)^{2} P[i, j]} \\
& \text { Correlation }=\frac{\Sigma_{i} \Sigma_{j}\left(i-\mu_{i}\right)(j-\mu j) P[i, j]}{\sigma_{i} \sigma_{j}} \\
& \text { Contrast }=\Sigma_{i} \Sigma_{j}(i-j)^{2} P[i, j]
\end{aligned}
$$

\subsection{Backpropagation}

Backpropagation merupakan algoritma pembelajaran yang terawasi dan biasanya digunakan oleh perceptron dengan banyak lapisan untuk mengubah bobot-bobot yang terhubung dengan neuron-neuron yang ada pada lapisan tersembunyi. Terdapat tiga fase didalam algoritma 
Backpropagation, yakni fase propagasi maju yang merupakan fase dimana sinyal-sinyal masukan akan

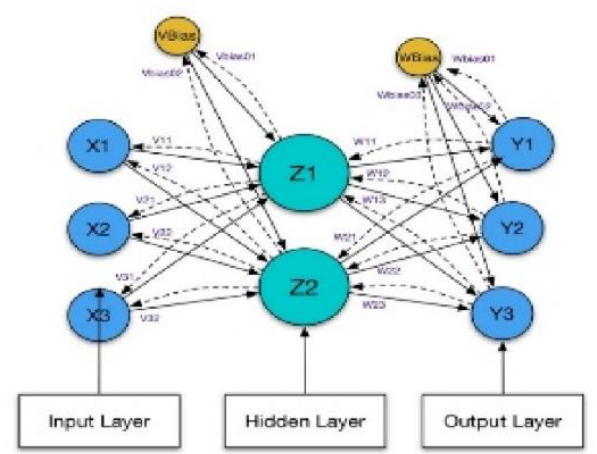

Gambar 3. Arsitektur Desain Backpropagation

dipropagasikan kepada layer diatasnya (hidden layer lalu output layer) menggunakan fungsi aktivasi yang telah ditentukan. Setelah itu fase yang kedua propagasi mundur untuk mengetahui kesalahan dari jaringan tersebut. Kemudian fase yang ketiga adalah fase modifikasi bobot yang digunakan untuk menghitung perubahan bobot yang terjadi dalam jaringan (Asmara, Puspitasari, Romlah, H, \& Romario, 2017).

Keterangan :

$\mathrm{X}_{1} \ldots . \mathrm{X}_{\mathrm{n}}$ adalah input layer.

$\mathrm{Z}_{1} \ldots . . \mathrm{Z}_{\mathrm{p}}$ adalah hidden layer.

$\mathrm{Y}_{1} \ldots . . \mathrm{Y}_{\mathrm{m}}$ adalah output layer.

$b_{1} \ldots . . . b_{s}$ adalah bias.

\subsection{Algoritma Backpropagation}

Algoritma pelatihan backpropagation adalah sebagai berikut :

Langkah 0 : inisialisasi bobot dan bias pada input layer dan hidden layer, epoch (perulangan), learning rate (laju pembelajaran).

$>$ Langkah 1 : jika epoch $\neq$ max epoch, lakukan langkah 2-9.

Fase I : Propagasi Maju (Feed Forward)

$>$ Langkah 2 : setiap nilai masukan menerima sinyal dan meneruskannya menuju ke lapisan tersembunyi (hidden layer).

> Langkah 3 : hitung semua nilai keluaran yang terdapat pada lapisan tersembunyi (hidden layer) $z_{j}(j=1,2, \ldots, p)$.

$z_{-} n e t_{j}=v_{j 0}+\sum_{i=1}^{n} x_{i} v_{i j}$

(10)

$z_{j}=f\left(z_{-} n e t_{j}\right)=\frac{1}{1+e^{-z_{-} n e t_{j}}}=f\left(z_{-} n e t_{j}\right)(1-$ $f\left(z_{-} n e t_{j}\right)$

(11)

Langkah 4 : menghitung nilai keluaran yang terdapat pada lapisan keluaran (output layer) $y_{k}(k=1,2, \ldots, m)$. $y_{-} n e t_{k}=w_{k 0}+\sum_{j=1}^{p} z_{i} w_{i j}$

(12)

$$
\begin{gathered}
y_{k}=f\left(y_{-} n e t_{k}\right)=\frac{1}{1+e^{-y_{-} n e t_{k}}}= \\
f\left(y_{\_} n e t_{k}\right)\left(1-f\left(y_{-} n e t_{k}\right)\right.
\end{gathered}
$$

Fase II : Propagasi mundur (Backpropagation)

Langkah 5 : menghitung faktor $\delta$ unit keluaran berdasarkan kesalahan disetiap unit keluaran $y_{k}(k=1,2, \ldots, m)$ $\left.y_{k}\right)$

$\delta_{k}=\left(t_{k}-y_{k}\right) f^{\prime}\left(y_{\text {net }_{k}}\right)=\left(t_{k}-y_{k}\right) y_{k}(1-$

Langkah 6 : menghitung suku perubahan bobot $W_{k j}$ dengan laju pembelajaran (learning rate)

$\Delta w_{k j}=\alpha \delta_{k} z_{j}$

(15)

$\mathrm{k}=1,2, \ldots, \mathrm{m} ; \mathrm{j}=1,2, \ldots, \mathrm{p} ;$

Langkah 7 : menghitung faktor $\delta$ unit tersembunyi (hidden layer) berdasarkan kesalahan disetiap unit tersembunyi $z_{j}(j=1,2, \ldots, p)$.

$\delta_{-} n e t_{j}=\sum_{k=1}^{m} \delta_{k} w_{k j}$

(16)

$\delta_{j}=\delta \_n e t_{j} f^{\prime}\left(z \_n e t_{j}\right)=\delta \_n e t_{j} z_{j}\left(1-z_{j}\right)$

(17)

Langkah 8 : menghitung suku perubahan bobot $V_{i j}$ dengan laju pembelajaran (learning rate)

$\Delta v_{i j}=\alpha \delta_{j} x_{i}$

(18)

$\mathrm{j}=1,2, \ldots, p ; i=1,2, \ldots, n$;

Fase III : Modifikasi bobot

Langkah 9 : menghitung semua perubahan bobot. Perubahan bobot garis yang menuju ke unit keluaran.

$w_{k j}($ baru $)=w_{k j}($ sekarang $)+\Delta w_{k j}$

(19)

$\mathrm{k}=1,2, \ldots, \mathrm{m} ; \mathrm{j}=1,2, \ldots, \mathrm{p} ;$

perubahan bobot garis yang menuju ke unit tersembunyi

$v_{k j}($ baru $)=v_{k j}($ sekarang $)+\Delta v_{i j}$

(20)

$\mathrm{j}=1,2, \ldots, p ; i=1,2, \ldots, n ;$

Langkah 10 : memperbaharui nilai epoch

epoch $=$ epoch +1

(21)

Hasil akhir dari proses pelatihan dengan menggunakan metode backpropagation adalah didapatkannya bobot-bobot $W_{1} \ldots W_{n}$ yang kemudian disimpan untuk pegujian jaringan. 


\section{Metodologi}

\subsection{Pengambilan Data}

Pengambilan data pada penelitian ini dilakukan secara manual melalui kamera smartphone dengan resolusi minimal 8MP. Proses pengambilan citra ini dibantu oleh aplikasi yang akan dibuat untuk mempotret ban mobil pada bagian tapak lebar atau Tread dengan jarak dan pencahayaan yang telah ditentukan. Selanjutnya, foto ban yang sudah diambil dikirimkan ke server melalui aplikasi tersebut untuk diproses. Kemudian, server mengirimkan ouputnya kembali ke smartphone.

Tabel 1. Jenis Variable, Jumlah dan Sumber Data

\begin{tabular}{|c|c|c|c|}
\hline No & $\begin{array}{c}\text { Jenis } \\
\text { Variabel }\end{array}$ & Jumlah & Sumber Data \\
\hline 1. & $\begin{array}{l}\text { Citra ban } \\
\text { mobil } \\
\text { kondisi } \\
\text { baik }\end{array}$ & 20 & $\begin{array}{l}\text { Bengkel mobil } \\
\text { khusus ban }\end{array}$ \\
\hline 2. & $\begin{array}{l}\text { Citra ban } \\
\text { mobil } \\
\text { kondisi aus } \\
\text { / Irregular } \\
\text { Wear }\end{array}$ & 20 & $\begin{array}{l}\text { Bengkel mobil } \\
\text { khusus ban dan } \\
\text { Toko ban mobil } \\
\text { bekas }\end{array}$ \\
\hline 3. & $\begin{array}{l}\text { Citra ban } \\
\text { mobil } \\
\text { kondisi aus } \\
\text { pada } \\
\text { bagian } \\
\text { tertentu / } \\
\text { Spot Wear }\end{array}$ & 20 & $\begin{array}{l}\text { Bengkel mobil } \\
\text { khusus ban dan } \\
\text { Toko ban mobil } \\
\text { bekas }\end{array}$ \\
\hline 4. & $\begin{array}{l}\text { Citra ban } \\
\text { mobil } \\
\text { kondisi } \\
\text { retak / } \\
\text { Tread Cut } \\
\text { Penetration }\end{array}$ & 20 & $\begin{array}{l}\text { Bengkel mobil } \\
\text { khusus ban dan } \\
\text { Toko ban mobil } \\
\text { bekas }\end{array}$ \\
\hline 5. & $\begin{array}{l}\text { Citra ban } \\
\text { mobil } \\
\text { kondisi } \\
\text { pecah / Cut } \\
\text { Brust }\end{array}$ & 20 & $\begin{array}{l}\text { Bengkel mobil } \\
\text { khusus ban dan } \\
\text { Toko ban mobil } \\
\text { bekas }\end{array}$ \\
\hline
\end{tabular}

\subsection{Pengolahan Data}

Pada proses ini, sistem akan mengolah citra masukan yang dimulai dari proses cropping citra untuk menjadi bagian ban yang rusak, kemudian hasil cropping tersebut dikonversi warna menjadi citra abuabu dengan menggunakan proses average citra. Selanjutnya citra hasil cropping yang telah di average dihitung nilai Grey Level Cooccurrence Matrix untuk mencari nilai dari energy, contrast, homogeneity, entropy, correlation. Langkah berikutnya yaitu pemberian label dengan menggunakan metode JST Backpropagation. Dalam metode JST Backpropagation ini terdapat tiga lapisan. Tiga lapisan tersebut antara lain, input layer, hidden layer, output layer.

\subsection{Flowchart}

Pada tahap ini diagram flowchart akan menjelaskan proses kerja sistem mulai dari sistem memasukkan citra masukan, melakukan proses pengolahan citra, melakukan proses ekstraksi tekstur menggunakan Grey Level Cooccurrence Matrix, hingga sistem melakukan klasifikasi menggunakan Jaringan Syaraf Tiruan dengan metode Backpropagation.

\section{Flowchart Input}

Proses input citra menjelaskan tentang bagaimana sistem memasukkan citra masukan. Proses input dalam diagram flowchart adalah sebagai berikut:

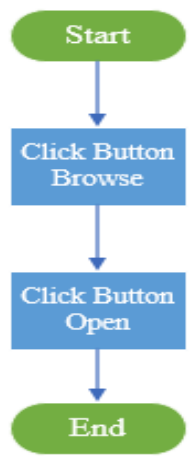

Gambar 4. Flowchart Input

Input citra pada aplikasi desktop dilak ukan dengan menekan Button Browse pada aplikasi, kemudian klik Open pada citra yang dipilih.

\section{Flowchart Ekstrasi Tekstur}

Metode yang digunakan untuk mengambil nilai tekstur ini menggunakan Grey Level Cooccurrence Matrix.

Proses pertama yaitu input citra RGB, kemudian dilakukan proses cropping. Hasil cropping kemudian dikonversi citra Grayscale. Proses selanjutnya, melakukan perhitungan GLCM untuk mendapatkan nilai ciri tekstur.
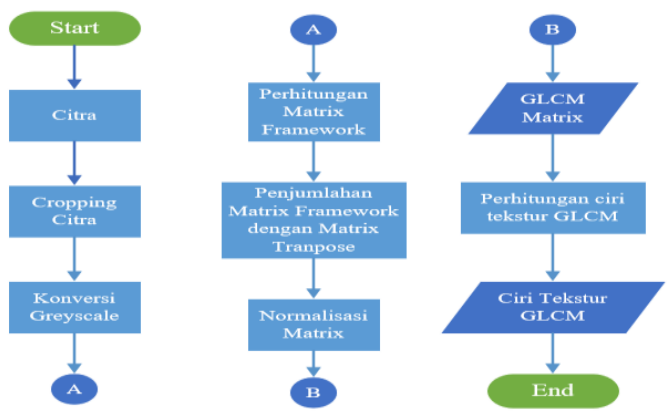

Gambar 5. Flowchart Ekstraksi Tekstur 


\section{Flowchart Klasifikasi}

Proses klasifikasi menggunakan Jaringan Syaraf Tiruan dengan metode Backpropagation.
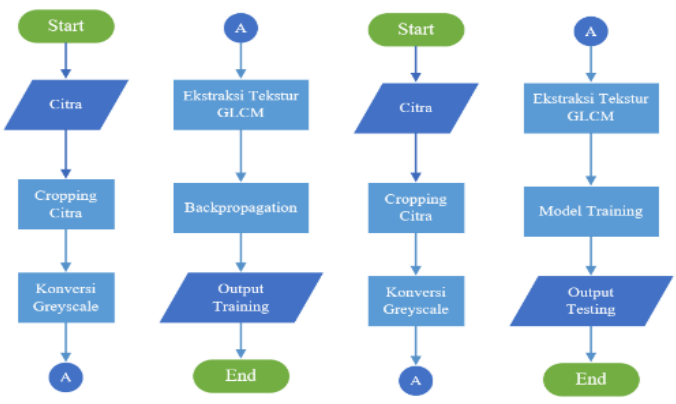

Gambar 6. Flowchart Klasifikasi

Setelah mendapatkan nilai ciri tekstur GLCM, kemudian nilai ciri tersebut dilakukan proses backpropagation untuk mendapatkan output training berupa model training. Pada proses testing model training ini digunakan sebagai acuan untuk proses klasifikasi untuk mendapatkan output.

\section{Analisa Uji Coba}

Pengujian akurasi dilakukan untuk menguji seberapa besar sistem identifikasi jenis kerusakan dengan menerapkan metode Backpropagation. Pada pengujian ini menggunakan data uji dengan jumlah 100 data yang terbagi menjadi 5 untuk setiap jenis kerusakan ban. Berikut data uji yang akan diuji :

Tabel 2. Data Uji

\begin{tabular}{|c|c|c|c|c|c|c|}
\hline $\begin{array}{l}\text { N } \\
\text { o }\end{array}$ & $\begin{array}{c}\text { Data } \\
\text { uji }\end{array}$ & $\begin{array}{c}\mathbf{J u} \\
\mathbf{m l a} \\
\mathbf{h}\end{array}$ & $\begin{array}{c}\text { Predi } \\
\text { ksi }\end{array}$ & $\begin{array}{c}\text { Ha } \\
\text { sil } \\
\text { Be } \\
\text { nar }\end{array}$ & $\begin{array}{c}\text { Ha } \\
\text { sil } \\
\text { Sal } \\
\text { ah }\end{array}$ & $\begin{array}{c}\text { Kelay } \\
\text { akan }\end{array}$ \\
\hline 1 & & 20 & Fine & 18 & 2 & Layak \\
\hline 2 & & 20 & $\begin{array}{c}\text { Irregu } \\
\text { lar } \\
\text { Wear }\end{array}$ & 15 & 5 & $\begin{array}{c}\text { Seten } \\
\text { gah } \\
\text { Layak }\end{array}$ \\
\hline 3 & & 20 & $\begin{array}{l}\text { Spot } \\
\text { Wear }\end{array}$ & 15 & 5 & $\begin{array}{c}\text { Seten } \\
\text { gah } \\
\text { Layak }\end{array}$ \\
\hline 4 & & 20 & $\begin{array}{l}\text { Tread } \\
\text { Cut } \\
\text { Penetr } \\
\text { ation }\end{array}$ & 16 & 4 & $\begin{array}{l}\text { Tidak } \\
\text { Layak }\end{array}$ \\
\hline 5 & & 20 & $\begin{array}{c}\text { Cut } \\
\text { Burst }\end{array}$ & 16 & 4 & $\begin{array}{l}\text { Tidak } \\
\text { Layak }\end{array}$ \\
\hline
\end{tabular}

Berdasarkan tabel 2. pengujian Akurasi didapat jumlah data benar yaitu 80 data, dan data salah yaitu 20 data. Detail pengujian akurasi dengan hasil benar dari masing-masing ban yaitu : fine 18 data benar dengan persentase $90 \%$, irregular wear 15 data benar dengan persentase $75 \%$, spot wear 15 data benar dengan persentase $75 \%$, tread cut penetration 16 data benar dengan persentase $80 \%$, cur burst 16 data benar dengan persentase $80 \%$. Sedangkan hasil pengujian akurasi dengan hasil salah dari masing-masing ban yaitu fine 2 data salah, irregular wear 5 data salah, spot wear 5 data salah, tread cut penetration 4 data salah, cur burst 4 data salah. Sehingga hasil akurasi yang didapat dari pengujian diatas sebagai berikut :

$$
\begin{aligned}
& \text { Akurasi }=\frac{\text { Jumlah data benar }}{\text { jumlah data keseluruhan }} \times 100 \% \\
& =\frac{80}{100} \times 100 \%=80 \%
\end{aligned}
$$

\section{Analisa Hasil}

Hasil pengujian akurasi pada 100 data yang uji menunjukkan angka persentase sebesar $80 \%$. Hasil akurasi tersebut tidak mencapai $100 \%$ dikarenakan beberapa hal, yaitu proses pengambilan citra ban mobil dilakukan di luar ruangan dengan menggunakan pencahaan berdasarkan kondisi cuaca saat itu, dan kondisi ban mobil yang sudah disatukan dengan beberapa ban yang menjadi tumpukan yang tidak dapat dipisahkan, pada ekstraksi tekstur menggunakan 5 ciri nilai tekstur yang terdiri dari energy, contrast, homogeneity, entropy, correlation, dan setiap nilai ciri pada masing masing data tidak menunjukkan perubahan nilai yang signifikan.

\section{Kesimpulan dan saran}

Berdasarkan hasil penelitian yang telah dilakukan dari analisis, uji coba pada Deteksi Kerusakan dan Kelayakan Ban Mobil Berdasarkan Ekstraksi Tekstur Menggunakan Gray Level Cooccurrence Matrix dengan Metode Backpropagation, maka dapat disimpulkan bahwa sistem dapat mengidentifikasi jenis kerusakan ban mobil dari citra ban mobil dengan mengimplementasikan metode Gray Level Cooccurrence Matrix untuk ekstraksi tekstur dan metode Backpropagation untuk klasifikasi setiap citra ban mobil dengan cukup baik. Dengan pengujian akurasi yang telah dilakukan pada 100 data citra menghasilkan persentasi akurasi sebesar $80 \%$, proses pengambilan citra, kondisi objek saat akan diambil citranya dan nilai parameter yang digunakan untuk proses klasifikasi, parameter nilai klasifikasi dan nilai ekstraksi ciri yang tidak signifikan merupakan faktor yang mempengaruhi tingkat keberhasilan akurasi yang didapat.

Saran yang dapat diberikan dari hasil penelitian yang telah dilakukan yaitu sebagai berikut.

1. Mencoba menggunakan parameter yang lebih banyak untuk proses klasifikasi. 
2. Menggunakan metode jaringan syaraf tiruan yang lain untuk proses training dan testing agar mendapat hasil akurasi yang lebih baik.

3. Menambahkan jumlah dataset agar persentasi akurasi menjadi lebih maksimal.

4. Membuat nilai parameter menjadi lebih signifikan pada masing jenis kelas untuk mendapatkan akurasi yang lebih baik.

\section{Daftar Pustaka:}

Agustian, T. (2014). Analisis Front Wheel Alignment (FWA) pada kendaraan Daihatsu Gran Max Pick Up. MIMBAR PENDIDIKAN, 9-20.

Andono, N. P., Sutojo, T., \& Muljono. (2017). Pengolahan Citra Digital. Yogyakarta: Andi.

Asmara, R. A., Puspitasari, D., Romlah, S., H, Q., \& Romario, R. (2017). IDENTIFIKASI KESEGARAN DAGING SAPI BERDASARKAN CITRANYA DENGAN EKSTRAKSI FITUR WARNA DAN TEKSTURNYA MENGGUNAKAN METODE GRAY LEVEL COOCCURRENCE MATRIX Rosa. Journal, I89 - I94.

Munir, R. (2004). Pengantar Pengolahan Citra. Bandung: Informatika Bandung.

Prasetyadi, J. (2016, November 15). Diambil kembali dari TEKNIK-OTOMOTIF.COM: https://www.teknikotomotif.com/2016/10/jenis-banpengertian-dan-kode-ban.html

Putra, D. (2010). Pengolahan Citra Digital. Dalam D. Putra, Pengolahan Citra Digital (hal. 1921). Jakarta: ANDI.

Rahmad, C., Astiningrum, M., \& Lesmana, A. P. (2018). PENGENALAN TAS RANSEL PADA CITRA DIGITAL DENGAN EKSTRAKSI FITUR TEKSTUR MENGGUNAKAN METODE GRAY LEVEL CO-OCCURRENCE MATRIX. Journal, 258-262. 